Fecha: 19/07/2021

Medio: El Mercurio de Valparaíso

Supl. : El Mercurio de Valparaiso

Tipo: Actualidad

Título: Expertos: hay desgaste y falta de liderazgos en derecha regional
Pág.: 5

Cm2: 658,5
Tiraje:

Lectoría:

Favorabilidad:
23.467

70.400

$\square$ No Definida
Joaquín Torres Tagle ciudades@mercuriovalpo.cl

U na noche de sorpresas electorales fue la de este domingo, cuando tanto Gabriel Boric como Sebastián Sichel vencieron a los favoritos de cada pacto en competencia para inscribir su nombre en la papeleta presidencial de noviembre.

Los analistas dela zona destacan el gran aumento de participación electoral en la región, pues mientras en las primarias de 2017 votaron 204.666 personas, ahora en 2021 sufragaron 347.156 votantes, una cifra notable pensando en el contexto de pandemia en que se desarrollaron los comicios.

En la primaria de Apruebo Dignidad (201.054 votos), los especialistas destacaron el des. pligue territorial y virtual del Frente Amplio, que subió de 45 mil votos a 118 mil. Por su parte, en Chile Vamos las dudas siguen, debido principalmente al papel que tendrá que jugar Sebastián Sichel para intentar recomponer al electorado del sector, que concurrió en menor cantidad -141.124 votos-, respecto a 2017 , donde lograron 151.112 (Cifiras con el 99,94\% de las mesas escrutadas).

Según Marcela Porto, académica de la Universidad Autónoma, la participación en la región da cuenta de una ciudadanía que "no ha dejado de implicarse en el devenir de lo politico desde el estallido social y que entiende que no da lo mismo votar por unou otro sector. Creo que esa democracia de electores de la que hablaba hace algunos años el PNUD, se está fortaleciendo con una democracia de ciudadanos y ciudadanas que participan no solo en los comicios electorales, sino que en una variada gama de organizaciones territoriales que se vieron claramente activadas desde el estallido social".

\section{NUEVA CORRELACIÓN}

Para Felipe Vergara, analista político de la Universidad Andrés Bello, siempre es bueno subir en votación, sin embargo, el 2017, al menos las prima rias que fueron del Frente Amplio, votaron en todo Chile algo más de 300 mil personas. "Estas eran distintas, en Apruebo Dignidad se jugaba mucho más. Evidentemente el Frente Amplio queda fortalecido. Especialmente, porque leganóal Partido Comunista y eso es un gran triunfo. El Partido Comunista, en ese escenario, es el gran perdedor".

Por su lado, Javiera Arce,

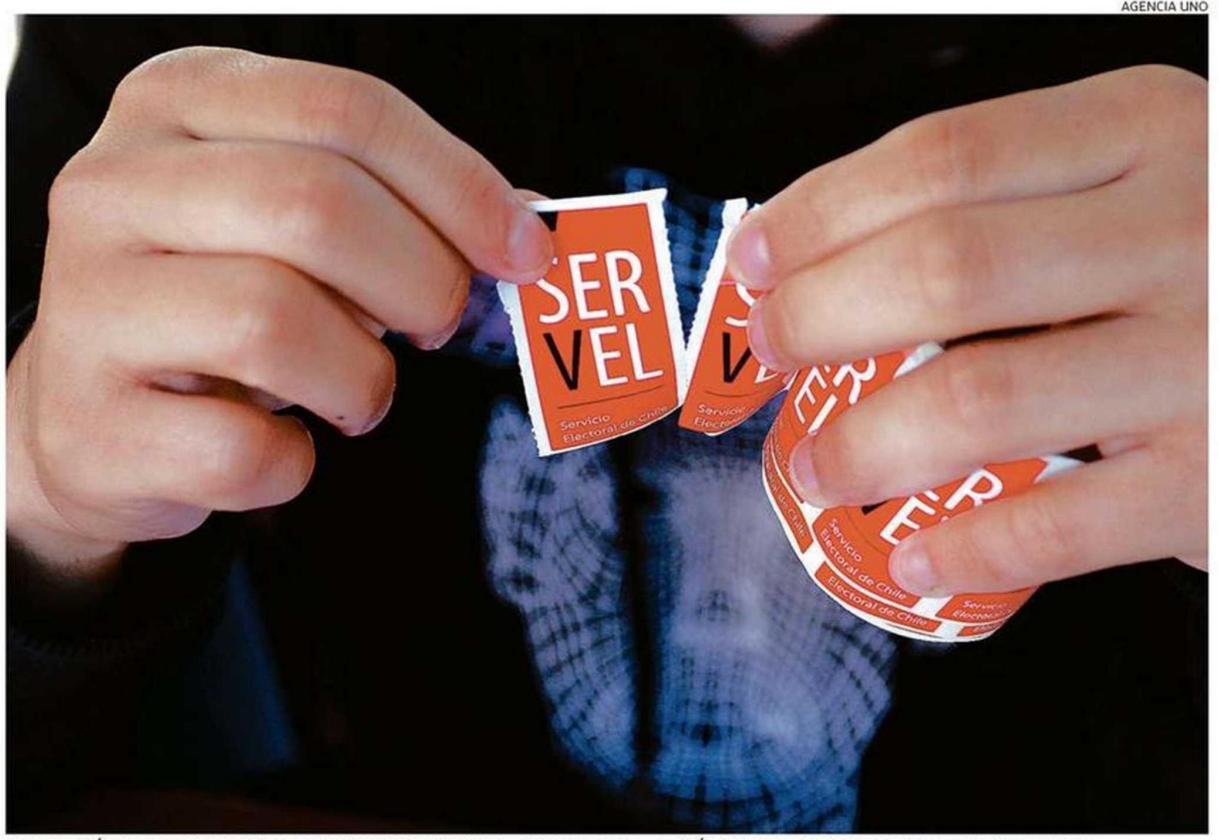

EN LA REGIÓN, G.BORIC OBTUVO 118 MIL VOTOS, D.JADUE 82 MIL, S.SICHEL 72 MIL, J.LAVIN 39 MIL,M.DESBORDES 15 MIL E I.BRIONES 13MIL

\title{
Expertos: hay desgaste y falta de liderazgos en derecha regional
}

POLÍTICA. Afirman que resultados revelan un cambio en mapa político de la zona.

cientista política de la Universidad de Valparaíso destaca el nuevo mapa político en la región. "Hay un claro y evidente cambio de correlación defuerzas políticas, se nota muchísimo que hay gobiernos de transformación a nivel local ya nivel regional, en este triunfo de Gabriel Boric se demostró muy fuerte los apoyos que recibió en la región, además recordar que Rodrigo Mundaca es el gobernador y es del Frente Amplio. Se observa un cambio muy interesante y muy convocante para esta primaria. Es evidente que ellos lograron avanzar muchísimo".

También destacó el rol que jugaron las autoridades delbloque en la zona."Determinante Macarena Ripamonti, Valeria Melipillán, y varias de los diputados, como Camila Rojas. Hay gente muy buena acá del Frente Amplio, que obviamente hizo una buena pega".

CÓDIGOS DIGITALES

El Doctor en comunicación de la PUCV, Claudio Elórtegui, detalló la situación en que queda el bloque frentamplista: "Hay una capacidad del Frente Amplio por seguir consolidando una presencia importante elec-
"La posición de la derecha sigue siendo muy compleja en la región de Valparaíso, ya lo vimos con la elección a nivel de gobernadores".

Claudio Elórtegui Doctor en comunicación

"Hay un claro y evidente cambio de correlación de fuerzas políticas (...) hay gobiernos de transformación a nivel local".

Javiera Arce Académica U.de Valparaíso

"La participación en la región da cuenta de una ciudadanía que no ha dejado de implicarse en el devenir de lo político desde el estallido".

Marcela Porto Académica U. Autónoma toral en la región de Valparaíso, transformándose en un bas. tión nacional de gran peso específico y de gran capacidad de articulación política, en condiciones territoriales adversas como ha sido la situación pandémica. Pero sobre todo por amoldarse muy bien a los códigos digitales".

Dela misma forma, destacó la campaña de G. Boric en la zona. "No hayque desmerecer lo que significó la campaña de Gabriel Boric en la región de Valparaíso y a nivel nacional, más allá de que el Frente Amplio tiene un peso importante en la zona, porque pudo haber pasado que ante un candidato que se hubiera visto más fuerte hubiese tenido un mejor despliegue de explicaciones y de encuadre de campaña, como podría haber sido Daniel Jadue, se hubiese movilizado también a un sector del FA por aventurar un apoyo a Jadue, eso finalmente no se dio".

CHILE VAMOS

Para Javiera Arce, integrante de la Red de Politólogas "respecto de Sebastián Sichel, estoy intrigada, porque saca menos votos que Daniel Jadue, se consolida pero tampoco es que haya un entusiasmo muy fuerte a través de su opción política, lo veo más bien débil, creo que va a tener problemas muy graves con los partidos políticos".

Para el Felipe Vergara, Doctor en Comunicación, Sichel ganó bien, pero "no creo que sea un triunfo que garantice un éxito futuro. La derecha la tiene muy dura, no tuvo una votación abrumadora como para afirmar que es una opción competitiva".

En tanto, el academíco Claudio Elórtegui definió como muy compleja la situación en que queda Chile Vamos. "La posición de la derecha sigue siendo muy compleja, muy dificil en la región de Valparaíso, ya lo vimos con la elección a nivel de gobernadores. Creo que la derecha en la región de Valparaíso ha tenido un desgaste tremendo, no tiene liderazgos regionales que se estén transformando en un relato atractivo, para en definitiva también captar nuevas áreas electorales de características más populares, como sí lo tuvo la propia UDI en la región de Valparaíso".

A lo que agregó: "la derecha viene adoleciendo de profesionalizar sus campañas políticas, evidentemente han

perdido presencia territorial mportante con sendas derrotas a nivel de alcaldias, todo eso viene a incrementar una cierta orfandad y desmotivación electoral de la derecha por sus cartas a nivel regional. Veremos si Sichel puede hacer un trabajo de recomposición frente a ese voto".

\section{IMPLICANCIAS}

Con respecto a los resultados generales, la magister en ciencias políticas, Javiera Arce, explicó que el candidato del Parido Comunista hizo una muy mala campaña. "Al final del día, la campaña de D.Jadue es tuvo llena de errores, errores muy complejos, en el sentido de que había que apostar hacia el centro, para ampliar el electorado y ellos decidieron quedarse en un nicho, avanzar hacia la Lista del Pueblo y no expandirse a los votos de centro, porque justamente está debilitada la alianza de centro que es la Concertación".

Para la Académica Marcela Porto, "El triunfo de Sichel impone a los partidos tradiciona les de la derecha el desafio de mirarse y pensarse en clave de cambio y apertura. Los resultados de las primarias de este domingo dejan más claro,no solo el mapa de fuerzas políticas que se medirán en los comicios de noviembre, sino que también, aquellas que estarán pre sentes en los próximos cuatro años en la política del país". 